\title{
A NOÇÃO MÍTICA DE JUSTIÇA NAS RELAÇÕES DE PODER NA TRAGÉDIA IFIGÊNIA EM ÁULIDA DE EURÍPIDES
}

\author{
JAA TORRANO* \\ Universidade de São Paulo
}

\begin{abstract}
Resumo. A análise hermenêutica da tragédia Ifigênia em Áulida de Eurípides verifica que nas relações de poder confundem-se e distinguem-se quatro pontos de vista consubstanciados em quatro graus conexos e necessários de verdade, de ser e de conhecimento, descritos como humano, heroico, numinoso e divino. Ao mesmo tempo essa análise nos mostra tanto a dinâmica dessa unidade quádrupla como estrutura básica do teatro de Eurípides quanto as refrações da justiça no interior dessa unidade múltipla. Palavras-chave. Tragédia grega; Eurípides; Ifigênia em Áulida; relações de poder.
\end{abstract} D.O.I. 10.11606/issn.2358-3150.v18i2p16-24

QuE NOÇÃo DE JUSTIÇA NOS REVELAM A PALAVRA DíKE E SEUS DERIVADOS NA tragédia Ifigênia em Áulida de Eurípides? Como essa noção mítica de justiça se explicita nas relações de poder?

Na tragédia Ifigênia em Áulida de Eurípides, a noção de justiça é invocada e reivindicada, descrita com adjetivos e verbos derivados de díke, mas essa noção sofre refrações, segundo diversos pontos de vista, correspondentes aos Deuses, aos Numes, aos heróis e aos mortais no horizonte político da pólis de Atenas na segunda metade do séc. v a.C.

No prólogo (1-162) no silêncio da noite em Áulida o rei Agamêmnon descreve a sua situação ao velho servo para que este ancião compreenda tanto as causas do infortúnio que aflige o rei quanto o sentido da missão de que o rei o incumbe.

Nas palavras de Agamêmnon, as causas do infortúnio têm dupla vertente e remontam por um lado ao juramento dos pretendentes de Helena instituído pelo pai Tindáreo como condição para as núpcias de sua filha Helena (49-70), e por outro lado a Páris, descrito como o "juiz das Deusas" que em retribuição ao seu juízo recebeu Helena por prêmio, e levou-

\footnotetext{
- Professor titular de língua grega e literatura grega na Universidade de São Paulo.

“-Artigo recebido em 25.set.2015 e aceito para publicação em 14.dez.2015.
} 
-a ao monte Ida, na Frígia (71-76). Menelau, marido de Helena, ultrajado, percorreu a Grécia e invocou os juramentos a Tindáreo segundo os quais os pretendentes "o deviam socorrer se injustiçado" (hos khrè boetheîn toîsin edikeménois, 79).

Essa reivindicação de justiça por Menelau é atendida e reúne os antigos pretendentes sob o comando de Agamêmnon, mas em Áulida a tropa reunida não pode navegar, e nesse impasse o adivinho Calcas anuncia o vaticínio do sacrifício da filha de Agamêmnon Ifigênia à Deusa Ártemis residente no solo de Áulida como condição para a frota grega navegar e destruir Troia (80-93). Menelau persuade seu irmão Agamêmnon à terrível ousadia de escrever à esposa Clitemnestra que enviasse a filha Ifigênia de Argos a Áulida sob o falso pretexto de casá-la com Aquiles para que navegassem para Troia, quando o vaticínio de Calcas era conhecido somente por Odisseu e os Atridas Menelau e Agamêmnon (94-107). Refazendo a decisão que lhe pareceu má, Agamêmnon reescreveu a carta revogando a ordem e incumbiu o velho servo de levá-la a Clitemnestra (108-14)

$\mathrm{O}$ ancião - que se diz um servo que como dote de Tindáreo à filha acompanhava a mulher de Agamêmnon desde a casa paterna - é naturalmente solidário da segunda decisão do rei, a de negar o assentimento ao sacrifício e de poupar a filha, e por isso inteiramente solícito e empenhado no cumprimento da nova ordem do rei.

Quando o rei manifesta inveja pela vida anônima sem perigos nem glória (17-19) e desgosto pela honraria cuja doçura quando próxima se revela dolorosa (21-3), e reitera esse desgosto em referência à honraria que o distingue como estratego eleito pelos aqueus (84-5), esse deslocamento do rei em sua honraria realça e prenuncia a mudança de decisão do rei, da conformidade para a inconformidade com o vaticínio de Calcas. A apreciação pessimista da condição de mortal com que Agamêmnon despede o servo é um lugar comum da piedade grega, que considera que todos os bens da vida dos mortais advêm da interação com os Deuses e por isso ao considerar a vida humana em si mesma, abstraída de sua interação com os Deuses, também a vê abstraída de todos os bens (16o-3).

No párodo (164-302), chegam a Áulida as mulheres de Cálcida para ver a frota de aqueus reunida. Essa contemplação e descrição dos navios, de suas origens e de seus chefes equipara o coro de mulheres de Cálcida à função das Musas no catálogo dos navios no canto iI da Ilíada. Essa associação do coro das mulheres da Cálcida com as Musas é ressaltada no final do párodo pela antevisão do porvir - conhecimento do futuro - e pela promessa de lembrar-se dessa visão da frota (295-302).

No primeiro episódio (303-542), na primeira cena (303-16), Menelau intercepta e captura o velho servidor e rouba-lhe a mensagem de Agamêm- 
non. O ancião chama por seu senhor, queixa-se de sofrer injustiça e denuncia Menelau por lhe tirar à força a carta das mãos e não anuir à justiça (314-16).

Na segunda cena (316-542) se dá o confronto entre os dois Atridas. Num primeiro momento (316-470), Menelau defende a primeira decisão de Agamêmnon em conformidade com o vaticínio de Calcas, e Agamêmnon defende a sua segunda decisão, contrária ao vaticínio. Num segundo momento (471-542) as posições de ambos se invertem: Menelau assume a segunda decisão de Agamêmnon, contrária ao vaticínio, e Agamêmnon reassume a sua primeira decisão, conforme o vaticínio.

No primeiro momento do confronto dos Atridas, Menelau argumenta que a atitude de Agamêmnon decorrente de sua segunda decisão não é estável, nem justa, nem clara, entendendo-se por clareza de certa forma a verdade, e constitui uma ruptura com os propósitos políticos de Agamêmnon de conquistar a honraria pública, o poder e a glória, e ainda uma ruptura com a promessa - voluntária, não coagida, - de sacrificar a filha, mediante o expediente de fazê-la vir de Argos a Áulida alegando que a casaria com Aquiles. Menelau declara esse recuo e envio da segunda carta uma fraqueza indigna de um verdadeiro líder e deplorável para a Grécia, que assim fica exposta ao riso e vilipêndio dos bárbaros (334-75).

O contra-argumento de Agamêmnon começa com um apelo ao pudor, pois primeiro acusa que o motivo de Menelau não era a honraria de Agamêmnon, mas o desejo vil de resgatar a má esposa perdida, e depois que a Deusa Esperança motivou o juramento dos pretendentes que os pôs à disposição de Menelau, prontos à demência, mas o divino não é insciente e pode perceber os juramentos mal firmados, feitos à força; e por fim contrapõe o bem de Menelau - a saber, punir a pior esposa, - às leis e à justiça do trato com os filhos, e conclui que "se tu não queres pensar bem, eu agirei bem" (378-401).

O coro é solidário com a segunda decisão de Agamêmnon e com a preservação da vida da filha (402-3); Menelau se sente abandonado e traído por Agamêmnon (404-14).

O mensageiro, não anunciado, de súbito anuncia a Agamêmnon que chegaram sua filha Ifigênia, sua esposa Clitemnestra e seu filho Orestes, e descreve a expectativa geral da multidão empolgada pela perspectiva das núpcias (414-39).

Agamêmnon despede o mensageiro para o interior da casa, e constata que caiu num jugo coercitivo, por intervenção de Nume que o supera em habilidade e que o reduz a insuportável perplexidade perante sua filha, sua mulher e seu filho. Reitera o louvor da vida obscura e anônima porque a supõe isenta das injunções a que nobres estão sujeitos, e reitera a atribuição da causa de seu infortúnio ao sequestro de Helena por Páris (440-68). 
O coro se apieda da perplexidade de Agamêmnon (469-70), e Menelau invoca Pélops, o avô comum dos Atridas, para fazer a retratação, e reconhecendo que não é justa a disparidade das sortes de ambos os Atridas aconselhou o rei a não matar a filha, ignorar o oráculo e dispensar a tropa (473-503).

Agamêmnon descreve a sua perplexidade perante os seus com a imagem do "jugo da coerção" (anágkes zeúgmat', 443), na constatação de que a habilidade do Nume o supera em habilidade, e a força da coerção o supera em poder (444-5). Essa imagem do jugo da coerção é comum ao Agamêmnon de Ésquilo (cf. anágkas édy lépadnon, "sob o jugo da coerção", Esq.Ag. 218), mas enquanto o protagonista esquiliano na mesma situação conclui pela liceidade de desejar com superfurioso furor o que lhe é imposto pela coerção, o protagonista euripidiano por ora se limita a constatar o Nume na coerção numinosa da "sorte coercitiva de executar a morte cruel da filha" (511-12).

Agamêmnon refuta os argumentos de Menelau em prol da decisão contrária ao oráculo (513-27), e mostra a Menelau o caráter inelutável dos elementos em jogo na execução do vaticínio de Calcas (528-42).

No primeiro estásimo (543-89), a estrofe louva a bem-aventurança advinda da participação modesta e prudente na Deusa Afrodite, a antístrofe louva o pudor como sabedoria e seus benefícios particulares e públicos, e o epodo evoca Páris, o juízo das Deusas e a paixão de Helena por Páris como causa da rixa entre gregos e troianos.

No segundo episódio (590-750), a ambiguidade se manifesta primeiro nas palavras de boas vindas que o coro de mulheres da Cálcida dirige à filha Ifigênia e à mãe Clitemnestra, quando se referem ao bom Nume dos grandes, dos poderosos e prósperos, que parecem Deuses aos mortais sem bom Nume (590-7). Neste caso, "bom Nume" significa simplesmente o poder e a prosperidade devidos à condição social proeminente, e "mortais sem bom Nume" significa simplesmente a condição social obscura e sem risco, antes mencionada pelo rei como objeto de desejo; a ambiguidade reside no ocultamento do sentido do Nume constatado antes pelo rei em presença do coro.

A ambiguidade torna possível o diálogo entre o pai e a filha. No encontro de ambos, as lágrimas incontidas do pai se explicam pela longa duração de "vindoura ausência" (651), o que para a filha (e a mãe) significa viagem nupcial, mas para o pai significa ida à casa de Hades, morte (666-71, 680).

Quando a tensão da ambiguidade se torna insuportável, o pai despede a filha para o interior da casa (685) e reafirma para a mãe o sentido nupcial da referida viagem (685-90) e para manter o ardil das núpcias da filha acrescenta que o noivo, Aquiles, filho de Peleu e da Deusa Tétis, educado pelo centauro Quíron, conduzirá a noiva a Ftia. O ardil do rei mostra 
o seu limite quando a mãe da noiva quer saber de sua própria participação na entrega da filha ao noivo (728). Diante da ardilosa opacidade das ordens do rei, a rainha invoca Hera, "rainha Deusa de Argos" (739) e reivindica a distinção espacial das competências do homem e da mulher: "Vai e faz o de fora! O de casa faço eu, / o que deve ser possível a filhas noivas" (740). O rei reconhece o fracasso de seu ardil junto a sua esposa, mas esse fracasso é inócuo ao rigor do jugo da coerção $(742-50)$.

No segundo estásimo (751-80o), a estrofe prevê a chegada dos gregos a Troia onde Cassandra inspirada por Deus é adivinha sob coerção mântica; a antístrofe prevê a chegada de Ares de brônzeo escudo remador de navio ao rio Simoente em Troia para reivindicar de Príamo a devolução de Helena, irmã dos Dióscoros divinos; o epodo prevê a destruição de Troia por Ares e as lágrimas e incertezas de Helena e das troianas. Por seu caráter proléptico e profético, o coro de Musas se distingue manifesto no coro das mulheres de Áulida.

No terceiro episódio (801-1035), encontrando-se com Aquiles, Clitemnestra descobre constrangida que Aquiles ignorava as esperadas núpcias da filha, nem recebeu nem fez propostas junto dos Atridas (801-54).

Antes de se separarem, desfeito o equívoco, o velho servidor confidente e mensageiro do rei intervém e revela a intenção por trás do ardiloso plano articulado por Menelau, a imolação da filha pelo pai à Deusa Ártemis (855-95).

Clitemnestra suplica a Aquiles que salve sua filha (900-16). Aquiles aceita a súplica e jura defender a filha e a pureza do seu nome indevidamente envolvido no dolo do ardil (919-74). Clitemnestra pergunta se também a filha deveria vir e suplicar pela própria vida perante Aquiles, o que este desaconselha e recomenda discrição, e propõe que a mãe suplique pela vida da filha ao pai, de modo a persuadir e tudo se resolver na própria família, sem ingerência externa (977-1035).

No terceiro estásimo (1036-97), a estrofe evoca a magnificência das núpcias de Peleu e Tétis, gloriadas pelas Musas Piérides, presentes ao banquete dos Deuses, Ganimedes servindo o vinho e as cinquentas Nereidas festejando junto à praia. A antístrofe evoca o vaticínio por Quíron de Peleu e Tétis serem pais da grande luz da Tessália. O epodo argumenta mostrando a inconsequência e impropriedade intrínseca à imolação da filha e prevenindo da impiedade e da inveja dos Deuses, o que constitui uma explícita condenação moral da morte de Ifigênia.

No quarto episódio (1098-508), Clitemnestra e a filha Ifigênia, cientes ambas do plano doloso, encontram-se com o rei Agamêmnon, não ciente de que ambas souberam do plano doloso. O rei pergunta se houve acordo de todos terem com ele vista confusa e turva, a rainha pergunta: "vais tu 
matar a filha - minha e tua?" e a resposta evasiva do rei é completamente clara para a rainha. Ante a tácita irrupção da verdade, o rei invoca "Senhora Parte, Sorte" e o seu Nume, cuja identidade a rainha denuncia com as palavras: "e meu e dela, mau Nume dos três!" Como se defendendo o rei pergunta: "que injustiça sofres?" e a resposta da rainha mostra a opacidade da noção de justiça nesse caso: "Isso perguntas? / Esse sentido mesmo não tem sentido." Ante tão tácita quão inequívoca irrupção da verdade o rei se cala para não mentir e não somar a impudência ao infortúnio (1098-145).

Os argumentos de Clitemnestra em defesa da vida da filha (11461208) e a súplica de Ifigênia por sua vida (1211-57) encontram no discurso de Agamêmnon (1255-76) a explicação das razões inelutáveis consequentes do jugo da coerção, acrescidas do decisivo sentimento de ser menor do que a Grécia e o devido a ela para que ela seja livre e respeitada. Este sentimento heroico do protagonista euripidiano (1270-75) corresponde no protagonista esquiliano ao sentimento da liceidade do superfurioso furor, pois um e outro se justificariam pelos mesmos votos de "que bem seja!" (êै gàr eíe, Esq.Ag. 218).

A monodia de Ifigênia (1276-335) elenca as causas de seu infortúnio, remontando aos vales da Frígia e montes de Ida, lamentando que acolhessem Páris, dito também Alexandre, remontando à rixa e ao juízo das Deusas Palas, Cípris e Hera, com Hermes, correio de Zeus, e com as consequentes primícias de Ártemis por Ílion, a morte de Ifigênia. A monodia lamenta ainda que Áulida acolhesse a frota grega e que Zeus soprasse adverso no Euripo e em geral variável, e lamenta afinal o doloroso gênero de efêmeros e sua infausta descoberta da necessidade e ainda os grandes sofrimentos causados pela Tindárida aos Danaidas. Esta apreciação pessimista da condição de mortal (aqui dito "efêmero") constitui um traço recorrente da piedade grega e reside no enfoque que abstrai a vida humana de sua inserção e interação com os Deuses, isolando-a dessa interação que lhe confere tudo o que nela há de bem e de magnificente.

Mostra-se a seguir como age o jugo da coerção além do âmbito da ação do rei Agamêmnon, como reagem Aquiles e Clitemnestra, e ao observar então como age o jugo da coerção, Ifigênia se converte da opinião contrária ao vaticínio na opinião conforme o vaticínio (1336-474).

Essa conversão percorre três momentos para se completar. O primeiro momento é quando a mãe admoesta a filha de que nas atuais circunstâncias não dispunha de requintes e não se podia evitar por pudor a conversa franca e direta com Aquiles, filho da Deusa Tétis, porque nisso residiria a única salvação possível (1336-44).

O segundo momento é a interlocução com Aquiles, quando este relata o clamor sanguinário de todos os gregos, e particularmente dos mirmí- 
dones, pelo apedrejamento de Aquiles porque este defendia a vida da noiva. Em contraste com esse clamor, Aquiles reitera sua promessa de usar as armas em defesa da vida da noiva, o que Clitemnestra declara justo (díkaia gár, 1355), e consequente com essa atitude, aconselha a mãe a interpor-se ainda que em vão para impedir que lhe levassem a filha (1345-68).

O terceiro momento é do discurso de rendição de Ifigênia à força inelutável da coerção, quando assume o ponto de vista da opinião conforme o vaticínio de Calcas, e instrui a mãe, seu defensor Aquiles e as mulheres da Cálcida como todos eles devem compreender a sua morte sacrificial: não com lúgubre luto, mas com jubilosa celebração, e particularmente sua mãe não deve ter rancor de seu pai por sua morte (1368-474).

O coro considera nobre a abnegação de Ifigênia, mas doente o que é da sorte e da Deusa (1402-3).

Aquiles admira e louva a beleza, nobreza e dignidade da rendição de Ifigênia, o que a torna noiva muito mais desejável, e reitera o seu desejo de ser o seu benfeitor e tê-la em casa (1404-15). À reiteração da promessa contida nessa confissão do desejo, Ifigênia replica que não morra por ela nem mate ninguém, mas deixe-a salvar a Grécia, se o podem (1416-20). Aquiles acata a decisão de Ifigênia, mas reafirma sua oferta de defendê-la, caso a iminência da morte, por ser terrível, altere sua decisão (1421-32).

No diálogo entre mãe e filha, Clitemnestra tenta superar o manifesto conflito de opiniões com o apelo à justiça nas relações entre ambas (hos par' hemôn oudèn adikései, tékhon, "nada meu te seja injusto, filha!", 1436), mas esse apelo torna ainda mais manifesto o conflito de opiniões. A filha pede à mãe que não a acovarde com o pranto, mas dispense-se a si mesma, às irmãs e ao irmão Orestes dos sinais de luto, lágrimas, tonsura e vestes negras. A dispensa do luto e o pedido de absolvição do pai por sua morte dela são gestos condizentes com a assunção heroica da interlocução com a Deusa. A mãe, no entanto, pode anuir a esse pedido da filha, mas não pode atendê-lo, dado o caráter inextricável do conflito de opiniões, e dada a impossibilidade para a mãe de renunciar à sua própria noção de justiça para assumir a perspectiva da opinião conforme o vaticínio de Calcas (1433-66).

Ifigênia, em abrupto contraste com o sentimento doloroso de sua mãe, exorta as moças a cantarem o peã à filha de Zeus por essa situação (tão gloriosa), exorta os Danaidas ao silêncio ritual e dá a quem compete e ao pai ausente instruções para o encaminhamento do sacrifício, declarando que dará "salvação vitoriosa aos gregos" (1467-74).

Como atendendo a sua própria exortação a cantar o peã a Ártemis, Ifigênia canta justificando o sacrifício e fixando uma visão glorificante dele. Ao cantar, Ifigênia se declara "letal à urbe de Ílion e dos frígios", consagra-se à Deusa Ártemis, reitera a interdição de prantos por serem incompatí- 
veis com a consagração, e conclama as donzelas a concelebrarem a Deusa nos exíguos ancoradouros de Áulida (1475-97).

Em diálogo com o coro, Ifigênia evoca a terra pátria e as figuras tutelares de sua pátria em reconhecimento de a terem criado para a salvação da Grécia, "luz da Grécia”, reiterando a aceitação da morte sacrificial, e por fim despede-se da luz de Zeus (1498-509).

O coro ecoa as palavras de Ifigênia, compartilhando de sua consagração e de sua visão glorificante do sacrifício (1510-31).

No êxodo (1532-629), entre duas falas de Clitemnestra que mostram a permanência insistente e a persistente verdade de um ponto de vista humano, o relato do mensageiro transita do ponto de vista humano, compartilhado pelo rei Agamêmnon (1547-52), para o ponto de vista heroico, instaurado pela fala de Ifigênia (1552-60), e a seguir para o ponto de vista numinoso, instaurado pela prece do Pelida Aquiles à Deusa Ártemis e configurado em seguida no milagre (thâ̂ma, 1581-9) e nas palavras com que o adivinho interpreta o milagre (1590-601).

Perante os sinais numinosos do milagre e a não menos numinosa hermenêutica deles proposta pelo adivinho, Clitemnestra permanece no âmbito do ponto de vista puramente humano (1615-18), o rei Agamêmnon retorna à cena para anunciar sua reconquistada convicção do ponto de vista heroico e formular votos de prosperidade unicamente compatíveis com a perspectiva heroica da interlocução com o Nume.

A generalização da possibilidade de acesso ao ponto de vista heroico como uma possibilidade ao rés do horizonte comum a todos os cidadãos é acenada pelo coro, quando este se congratula com Clitemnestra pelo relato do mensageiro (1613-14) e quando solidário se despede do rei Agamêmnon, formulando-lhe votos de boa viagem a Troia, bela vitória e bom regresso à pátria.

Observa-se, em comparação com o párodo da tragédia Agamêmnon de Ésquilo, a redistribuição das instâncias do divino entre as personagens do drama Ifigênia em Áulida de Eurípides: enquanto a personagem Agamêmnon instaura o ponto de vista heroico no homônimo drama de Ésquilo, essa personagem no drama euripidiano oscila tanto entre a opinião conforme o vaticínio de Calcas e a opinião contrária ao mesmo vaticínio quanto entre o ponto de vista humano, coincidente com a segunda opinião, contrária ao vaticínio, e o ponto de vista heroico, coincidente com a primeira opinião, conforme o vaticínio. A personagem Ifigênia, que no drama de Ésquilo é calada "com violência e muda força de mordaça" (Esq.Ag.237), no drama de Eurípides transita de um ponto de vista puramente humano, compartilhado pela mãe, para um ponto de vista decididamente heroico, de interlocução com o divino, mediante a abrupta ruptura e superação do âmbito puramente humano de sentimento de dor da mãe. 
Na perspectiva do pensamento mítico grego, observa-se que nas relações de poder confundem-se e distinguem-se quatro pontos de vista consubstanciados em quatro graus conexos e necessários de verdade, de ser e de conhecimento, descritos como humano, heroico, numinoso e divino. A análise hermenêutica consequente dessa perspectiva nos mostra a dinâmica dessa unidade quádrupla como estrutura básica do teatro de Eurípides e também as refrações da justiça no interior dessa unidade múltipla.

\section{$*$}

Title. Justice and power relationships in Euripides' Iphigenia at Aulis

Abstract. The hermeneutical analysis of Euripides' tragedy Iphigenia at Aulis confirms that four points of view are confused and distinguished in the power relationships. They are consubstantiated in four connected and necessary grades of truth, being and knowledge. These four grades are the human, heroic, numinous and divine ones. Meanwhile, this analysis shows that the dynamics of this fourfold unity is a basic structure of Euripides' theatre and it also shows the deflection of justice through that manifold unity.

Keywords. Greek tragedy; Euripides; Iphigenia at Aulis; power relationships. 